\title{
A cross-sectional examination of modifiable risk factors for chronic disease among a nationally representative sample of youth: are Canadian students graduating high school with a failing grade for health?
}

\author{
Scott T Leatherdale ${ }^{1 *}$ and Vicki Rynard ${ }^{2}$
}

\begin{abstract}
Background: Substance use and weight gain among youth increase the risk for future disease. As such, the purpose of this study is to examine how many Canadian youth are currently failing to meet substance use and weight gain related public health guidelines.

Methods: Data from the 2010-11 Youth Smoking Survey were used to examine grade 9 to 12 students meeting seven different guidelines by sex and by grade.

Results: Among Canadian youth, 8.8\% were current smokers, 18.8\% were current marijuana users, 25.5\% were current binge drinkers, $22.5 \%$ were considered overweight or obese, $31.2 \%$ did not meet physical activity guidelines, $89.4 \%$ exceeded sedentary behaviour guidelines, and $93.6 \%$ reported inadequate fruit and vegetable intake. The mean number of risk factors per student was $2.9( \pm 1.2)$; only $0.5 \%$ of youth reported having none of the risk factors.
\end{abstract}

Conclusion: Students rarely met all seven public health guideline examined, and the vast majority of actually reported having two or more modifiable risk factors for disease.

Keywords: Obesity, Physical activity, Tobacco, Alcohol, Marijuana, Diet, Youth

\section{Background}

Age-related increases in substance use and excess weightgain that occur among youth are cause for concern as they are associated with numerous negative health outcomes [1-9]. Substance use and obesity (and the correlates of obesity) tend to be established during adolescence [2,10-12], and most Canadian youth exhibit one or more of these risk factors for future morbidity [10-15]. For instance, according to data from grade 9 to 12 students in the 2008 Youth Smoking Survey (YSS), 8.9\% were current smokers (increasing from $6.8 \%$ to $15.6 \%$ between grade 9 and 12), $18.8 \%$ were current marijuana users (increasing from $17.7 \%$

\footnotetext{
* Correspondence: sleather@uwaterloo.ca

'School of Public Health and Health Systems, University of Waterloo, 200 University Avenue, Waterloo ON, N2L 3G1, Canada

Full list of author information is available at the end of the article
}

to $29.1 \%$ between grade 9 and 12), and $27.0 \%$ were current binge drinkers (increasing from $21.0 \%$ to $50.8 \%$ between grade 9 and 12) [10]. Data from the 2007-09 Canadian Health Measures Survey (CHMS) suggest that among Canadian youth aged 15 to $19,31 \%$ of boys and $26 \%$ of girls are overweight or obese [12]. In terms of the correlates for obesity, the 2007-09 CHMS identified that only $9 \%$ of boys and $4 \%$ of girls accumulate 60 minutes of moderate-to-vigorous physical activity (PA) on at least 6 days a week [13], the 2008 YSS identified that the average daily sedentary screen time among Canadian youth was 7.8 ( \pm 2.3 ) hours per day [11], and the 2011 Canadian Community Health Survey (CCHS) identified that only $43.7 \%$ of males and $44 \%$ of females aged 12 to 19 years consumed five servings of fruits and vegetables daily 
[14]. It is critical to promote healthier lifestyles among Canadian youth.

While the aforementioned modifiable risk factors for disease are individually important, evidence suggests that having more than one risk factor can act to amplify the risk [15]. Considering that it is common for youth to exhibit more than one of these risk factors [11,12,16-20], it is not only important to understand how many Canadian youth are currently failing to meet the Canadian public health guidelines associated with these risk factors [3,21-26], but it is also important to determine how many youth are at potentially increased risk due to co-occurrence of more than one risk factor. Although some evidence has previously been published on the co-occurrence of modifiable risk factors among youth in Canada using data from the National Longitudinal Survey of Children and Youth (NLSCY) [27-29], that evidence is subject to some major limitations for informing current prevention programming. For instance, although the most recent evidence presented by Alamian and Paradis [27] are based on longitudinal data, there are four limitations associated with that evidence which warrant new research in this domain: 1) the most recent wave of data examined were from 2004-2005, as such those data are no longer as informative for informing current prevention programming as data from 2010; 2) they examined ever use of tobacco and ever use of alcohol whereas current tobacco or current alcohol use may be more informative, 3) due to changes in guidelines, the measures for tobacco, alcohol use, sedentary behaviour and PA were not operationally defined according to definitions within the current prevention guidelines; and 4) the according to Statistics Canada [30], the NLSCY was only nationally representative to the original sample population (Cycle 1). Although these earlier reports are important [27-29], additional investigation into this issue is warranted with the most current nationally representative youth data available.

Considering schools provide an effective environment for intervening with youth [31], and international guidelines recommend a comprehensive approach to achieving health promoting schools [32,33], the objective of this study is to use nationally representative data collected from grade 9 to 12 students to determine the prevalence for the these major modifiable risk factors for disease and examine how prevalence rates and co-occurence of risk factors change across grades.

\section{Methods}

\section{Design}

This study used data collected from 31,396 students in grades 9 to 12 who responded to the substance use section of the 2010-11 Canadian Youth Smoking Survey (2010 YSS); a nationally representative school-based survey of youth in Canada. In brief, the population of interest for the data used in this study consisted of all young Canadian residents in grades 9 to 12 attending public and private secondary schools in nine Canadian provinces; youth residing in the Yukon, Nunavut, the Northwest Territories, and New Brunswick were excluded from the population of interest, as were youth living in institutions or on First Nation Reserves, and youth attending special schools or schools on military bases. While New Brunswick participated in all prior cycles of YSS, the provincial government chose not to participate in 2010/2011. The survey design and sample weights allow us to produce population-based weighted sample estimates within this manuscript. The University of Waterloo Office of Research Ethics and appropriate School Board and Public Health Ethics committees approved all procedures. Detailed information on the 2010 YSS sample design, methods, response rates and measures are available at www.yss.uwaterloo.ca/results/yss10_user_guide_english_ ver5_20120411.pdf.

\section{Measures}

The operational definitions for the measures used in this manuscript are consistent with previous research using national standards $[10,11,34-36]$ or current national public health guidelines $[22,23,25,26]$. This allows us to be consistent with the standards set forth and used by the different Canadian public health authorities who are responsible for (a) determining what risk factor measures are health promoting or health inhibiting, and (b) developing and implementing population-level strategies for intervening. For instance, our measures of tobacco use, alcohol use, marijuana use, obesity, and fruit and vegetable intake are consistent with the surveillance measured used by Health Canada and the Public Health Agency of Canada (PHAC), and our measures of physical activity and sedentary behaviour are consistent with the guidelines developed by the Canadian Society for Exercise Physiology and used by Health Canada and PHAC.

\section{Substance Use}

Tobacco use was assessed by asking respondents, "Have you ever smoked 100 or more whole cigarettes in your life?" and "On how many of the last 30 days did you smoke one or more cigarettes?". Consistent with previously validated measures of current smoking [36], students who reported ever smoking 100 cigarettes and any smoking in the previous 30 days were classified as current smokers. Marijuana use was assessed by asking respondents, "In the last 12 months, how often did you use marijuana or cannabis? (a joint, pot, weed, hash...)". Those who reported marijuana use once a month or more were classified as current marijuana users. Binge drinking (5 or more drinks on one occasion) alcohol use was assessed by asking respondents, "In the last 12 months, how often did you 
have 5 drinks of alcohol or more on one occasion?". Those who reported binge drinking once a month or more were classified as current binge drinkers.

\section{Overweight/Obesity and Correlates of Overweight/Obesity}

Using previously validated measures of self-reported height and weight [35], Body Mass Index (BMI) was calculated for each student using the measures of weight $(\mathrm{kg})$ and height $(\mathrm{m})\left(\mathrm{BMI}=\mathrm{kg} / \mathrm{m}^{2}\right)$. Weight status was then determined using the BMI classification system of the World Health Organization [26] based on age and sex adjusted BMI cut-points. Using previously validated measures [35], physical activity was measured by asking respondents how many minutes of hard PA they engaged in on each of the last seven days. Consistent with the Canadian PA guidelines for youth [22], respondents who did not report performing hard PA a day for at least three out of the last seven days were classified as being inactive. Respondents were asked to report the average number of hours per day that they spent (a) texting or talking on the phone, (b) e-mailing or instant messaging, (c) playing video games, (d) playing or surfing on a computer, or (e) watching TV or movies. Respondents could choose from "none," "less than 1 hour a day," " 1 to 2 hours a day," "more than 2 hours a day but less than 5 hours a day," or " 5 or more hours a day" for each category. We then calculated a conservative estimate of the mean sedentary behaviour time per day based on the sum of lowest values for each response category reported, except for the category "less than 1 hour per day" where 0.5 hours was used. Consistent with the Canadian sedentary behaviour guidelines for youth [23], respondents were classified as highly sedentary if they reported an average of more than two hours of sedentary behaviour a day. Respondents were asked to report how many servings of fruits and/or vegetables they eat on a usual day. Consistent with the Canada Food Guide fruit and vegetable consumption recommendations for teens [25], males who reported less than eight servings per day and females who reported less than seven servings per day were classified as having inadequate fruit and vegetable consumption ${ }^{\mathrm{a}}$.

\section{Analyses}

Descriptive analyses of the risk factors were examined by sex and by grade. As evident in Table 1, these data were not normally distributed. We also determined the total number of risk factors per student to examine the co-occurence of multiple risk factors by sex and by grade. In all analyses, survey weights were used to adjust for non-response between provinces and groups, thereby minimizing any bias in the analyses caused by differential response rates across regions or groups. For missing data, imputations were not performed; as such, the prevalence of each risk factor was based on the sample that had complete data for that particular indicator. This allowed us to preserve as much of the sample data as possible. Specific details on the amount of missing data for the measures in 2010-11 YSS have been previously published online [http://www.yss.uwaterloo.ca/_global/documents/ yss10_frequencies_publicuse_english_ver3_20120125.pdf]. When examining the co-occurrence of multiple risk factors by grade and sex, respondents with missing data for any one or more indicators were excluded from the analyses. Significance was assessed using the chi-square test. The statistical package SAS 9.2 was used for all analyses [37].

\section{Results}

Table 1 presents estimates of risk factor prevalence by sex for the population. The population was $51.8 \%(\mathrm{n}=849,600)$ male and 48.2\% $(\mathrm{n}=791,400)$ female. Overall, $8.8 \%(\mathrm{n}=$ $143,500)$ were current smokers, $18.8 \%(n=297,200)$ were current marijuana users, and 25.5\% ( $\mathrm{n}=408,800)$ were current binge drinkers. Males were more likely than females to be current smokers $(\mathrm{p}<0.001)$, current marijuana users $(\mathrm{p}<0.001)$, and current binge drinkers $(\mathrm{p}<0.001)$. The mean BMI among males was $22.6( \pm 4.5) \mathrm{kg} / \mathrm{m}^{2}$ and $21.4( \pm 3.9) \mathrm{kg} / \mathrm{m}^{2}$ among females. We identified that $22.5 \%$ $(\mathrm{n}=276,100)$ of Canadian youth were considered overweight or obese for their age and sex, with males being substantially more likely than females to be considered overweight or obese $(\mathrm{p}<0.001)$. BMI data were missing from $24.0 \%$ of male students and $26.8 \%$ of female students. In total, $31.2 \%(\mathrm{n}=464,300)$ of students did not meet the PA guideline, $89.4 \%(\mathrm{n}=1,463,900)$ were considered as being highly sedentary, and $93.6 \%(n=1,487,400)$ reported inadequate fruit and vegetable consumption. Females were more likely than males to be inactive $(\mathrm{p}<0.001)$, whereas males were more likely than females to report inadequate fruit and vegetable consumption $(\mathrm{p}<0.001)$; sedentary behaviour did not significantly vary by sex $(\mathrm{p}=0.06)$. The mean number of co-morbid risk factors among respondents was $2.9( \pm 1.2)$. Among Canadian students in grades 9 to 12 , only $0.5 \%(n=6,000)$ reported having none of the risk factors and only $0.3 \%(n=2,800)$ reported having all 7 risk factors. The mean number of co-morbid risk factors was higher among males $[3.0( \pm 1.2)]$ than females $[2.8( \pm 1.1)](\mathrm{p}<0.001)$.

Figure 1 displays changes in the prevalence of risk factors by grade. As shown, there were consistent increases in the prevalence of current smoking, current marijuana use, current binge drinking, and physical inactivity among students across grades 9 to 12 . The largest relative increases between grade 9 and 12 were observed for smoking (170\%) and current binge drinking (167\%). There was also a $124 \%$ relative increase in the prevalence of current marijuana use and a $64 \%$ relative increase in the prevalence physical inactivity across grade 9 to 12 . There appears to be a ceiling effect for students being considered highly sedentary or having inadequate fruit and vegetable 
Table 1 Descriptive statistics for estimates of risk factor prevalence by sex for the population, 2010-2011, Canada

\begin{tabular}{|c|c|c|c|c|}
\hline & & Male & Female & Total \\
\hline & & $\begin{array}{l}\overline{(n=849,600)} \\
\%^{\mathrm{a}}\end{array}$ & $\begin{array}{l}(n=791,400) \\
\%^{a}\end{array}$ & $\begin{array}{l}(n=1,641,000) \\
\%^{a}\end{array}$ \\
\hline \multirow[t]{4}{*}{ Grade } & 9 & 24.8 & 25.1 & 24.9 \\
\hline & 10 & 26.1 & 25.4 & 25.8 \\
\hline & 11 & 25.5 & 25.7 & 25.6 \\
\hline & 12 & 23.6 & 23.8 & 23.7 \\
\hline \multirow[t]{2}{*}{ Current Smoker (based on cigarettes only) } & Yes & 9.7 & 7.7 & 8.8 \\
\hline & No & 90.3 & 92.3 & 91.2 \\
\hline \multirow[t]{2}{*}{ Current Marijuana Use } & Yes & 22.3 & 15.3 & 18.8 \\
\hline & No & 77.7 & 84.7 & 81.2 \\
\hline \multirow[t]{2}{*}{ Current Binge Drinking } & Yes & 27.7 & 23.1 & 25.5 \\
\hline & No & 72.3 & 76.9 & 74.5 \\
\hline \multirow[t]{2}{*}{ Weight Status } & Overweight/Obese & 29.1 & 15.2 & 22.5 \\
\hline & Normal Weight & 70.9 & 84.8 & 77.5 \\
\hline \multirow[t]{2}{*}{ Physical Activity Level } & Inactive & 23.9 & 39.0 & 31.2 \\
\hline & Active & 76.1 & 61.0 & 68.8 \\
\hline \multirow[t]{2}{*}{ Sedentary Behaviour Level } & High & 89.8 & 89.1 & 89.4 \\
\hline & Moderate / Low & 10.2 & 10.9 & 10.6 \\
\hline \multirow[t]{4}{*}{ Fruit / Vegetable Consumption } & Inadequate & 94.5 & 92.7 & 93.6 \\
\hline & Adequate & 5.5 & 7.3 & 6.4 \\
\hline & & Male & Female & Total \\
\hline & & $\begin{array}{l}\overline{(n=577,600)} \\
\%^{b}\end{array}$ & $\begin{array}{l}\overline{(n=518,400)} \\
\%^{b}\end{array}$ & $\begin{array}{l}(n=1,096,000) \\
\%^{b}\end{array}$ \\
\hline \multirow[t]{8}{*}{ Number of Risk Factors } & All 7 & 0.3 & $\#$ & 0.3 \\
\hline & 6 & 2.5 & 1.9 & 2.2 \\
\hline & 5 & 7.4 & 5.9 & 6.7 \\
\hline & 4 & 18.4 & 14.2 & 16.4 \\
\hline & 3 & 32.7 & 35.8 & 34.2 \\
\hline & 2 & 33.4 & 33.2 & 33.3 \\
\hline & 1 & 5.1 & 7.9 & 6.4 \\
\hline & None & \# & 0.9 & 0.5 \\
\hline
\end{tabular}

a weighted population estimate where missing data are excluded from the estimate.

b weighted population estimate where respondents were excluded if any individual risk factor data were missing.

1 Prince Edward Island, Nova Scotia, Newfoundland \& Labrador.

${ }^{2}$ Quebec does not include students in Grade 12.

${ }^{3}$ Alberta, Saskatchewan, Manitoba.

\# Data not reportable due to low cell size.

consumption, as there was only a $3 \%$ relative increase in the prevalence of being highly sedentary and a $1 \%$ relative increase in the prevalence of having inadequate fruit and vegetable consumption across grades 9 and 12 . Overweight/obesity was the only risk factor where there was a relative decline (5\%) in prevalence across grade 9 and grade 12 .

The mean number of co-morbid risk factors for students was $2.6( \pm 1.0)$ in grade 9, $2.8( \pm 1.1)$ in grade 10, 3.0 $( \pm 1.2)$ in grade 11 , and $3.3( \pm 1.3)$ in grade 12. Figure 2 displays the changes in the prevalence of co-morbid risk factors by grade. Although there were no differences by grade for student reporting either no risk factors or all seven risk factors, it appears that the co-occurence of risk factors tends to be more common among students in higher grades. Interestingly, there also appears to be a transition point for the co-occurrence of three or more risk factors as a function of grade. For instance, there was a $61 \%$ relative decrease in the prevalence of respondents reporting only one risk factor and a $48 \%$ relative decrease in the prevalence of respondents reporting two risk factors across grade 9 to 12 . Conversely, there was a 


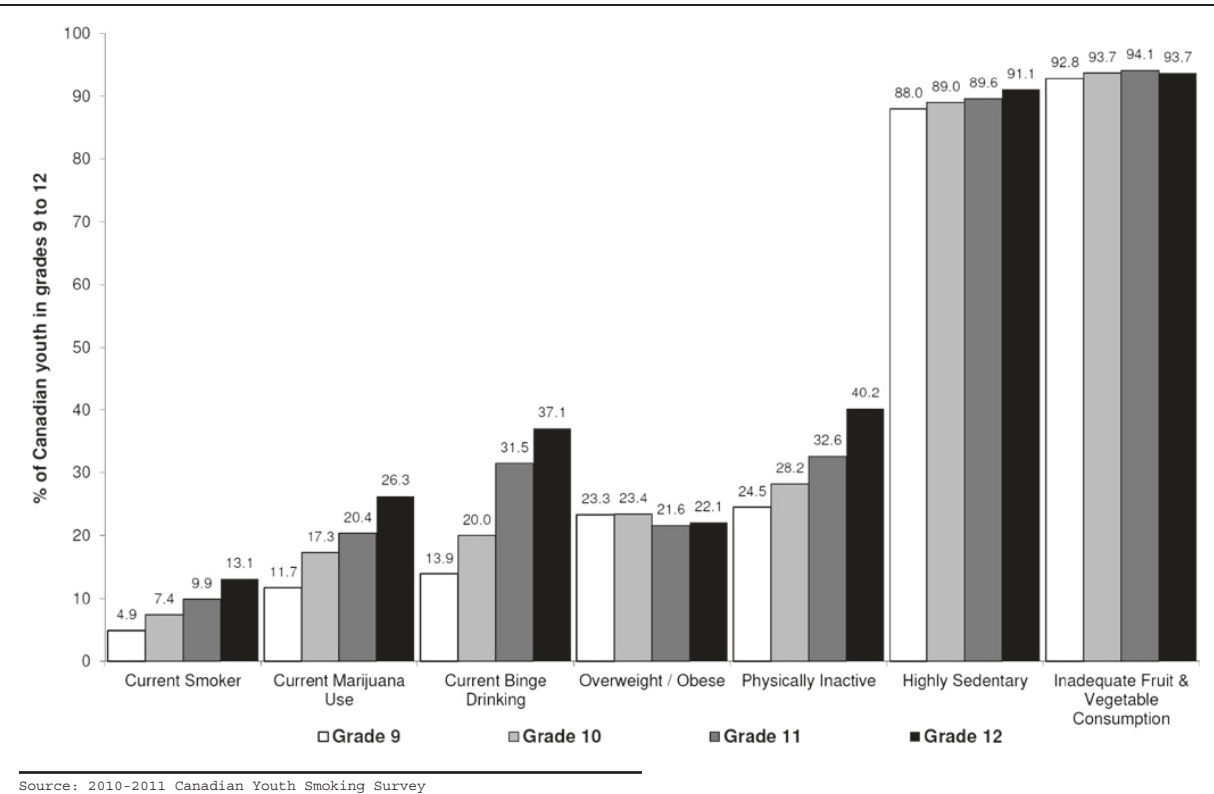

Figure 1 Prevalence of major modifiable risk factors for chronic disease among Canadian students by grade.

$112 \%$ relative increase in the prevalence of respondents reporting four risk factors, a $296 \%$ relative increase in the prevalence of respondents reporting five risk factors, and a $432 \%$ relative increase in the prevalence of respondents reporting six risk factors across grade 9 to 12 .

\section{Discussion}

These data indicate that there is an urgent need to improve the health profile of Canadian secondary school students in order to avoid a large future burden of preventable disease. Not only was it rare to find students who meet all of the public health guideline indicators examined, but the vast majority of Canadian students actually reported having two or more modifiable risk factors for disease. This is concerning as the Centers for Disease Control and Prevention (CDC) report that the modifiable risk factors examined in this report represent the largest threats to future adult morbidity and mortality [38]. Considering

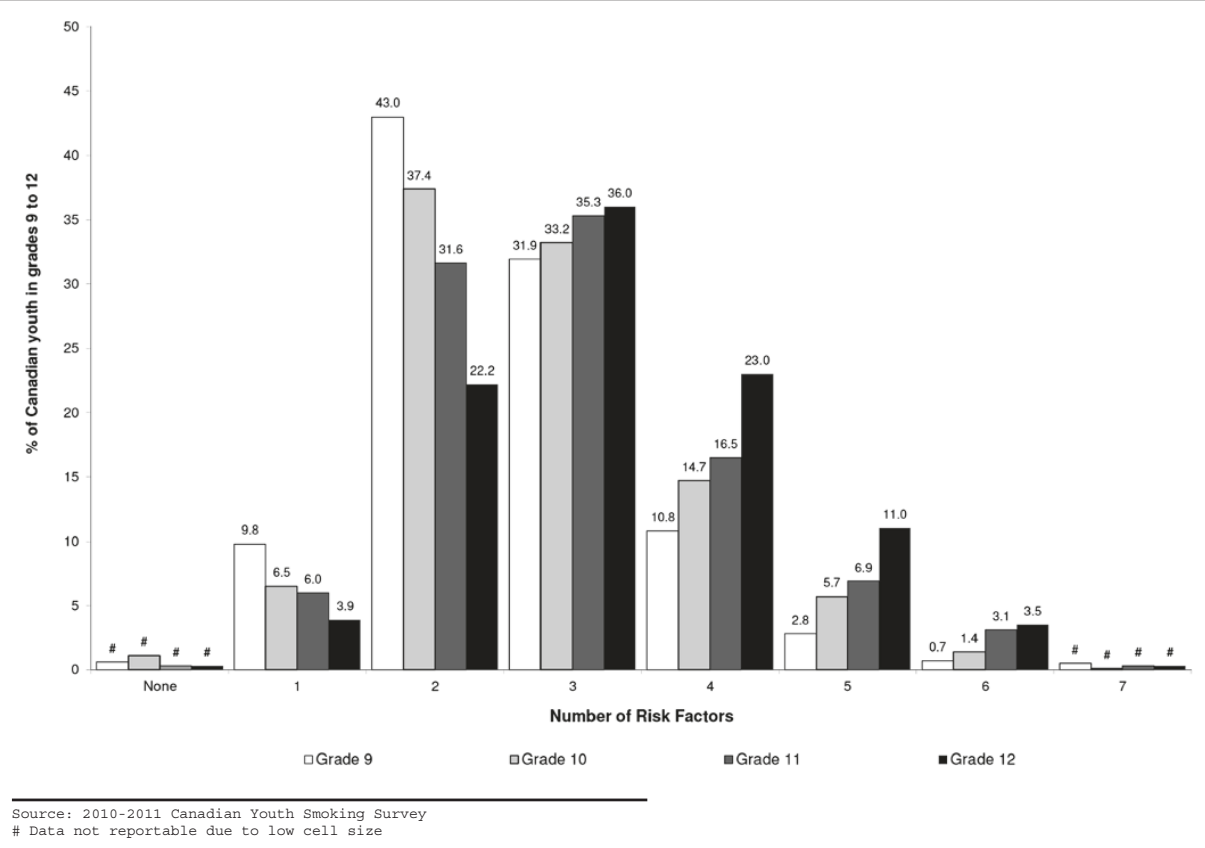

Figure 2 Prevalence of co-occurrence of modifiable risk factors for chronic disease among Canadian students by grade. 
that the prevalence estimates we present are consistent with U.S. estimates from the 2010-11 Youth Risk Behavior Surveillance System (YRBSS)[39] we are confident in these results.

Given the health and social effects associated with high risk substance use, and that substance abuse among adults is typically established during adolescence [10,39-41], the large number of Canadian youth we identified as being frequent substance users suggests that there is a need for ongoing and improved substance use prevention within Canadian secondary schools. The substantial variation in prevalence rates we identified across grades is consistent with previous research [10] and highlights the importance of targeting prevention interventions to different grades within a school. This also demonstrates why surveillance reports among youth that only present overall estimates may be misleading. There are often large differences between the prevalence rates when a student first starts secondary school (grade 9) to when they are preparing to leave secondary school (grade 12). Furthermore, considering that evidence has previously demonstrated that poly-substance use is common among Canadian youth $[27,41]$, and our data suggest that the rates of co-morbid risk factors increase by grade, these results suggest that the current approach in school-based prevention programming, where most school-based programs do not focus on poly-substance prevention [42,43], are likely flawed. There is clearly a need to test and robustly evaluate the impact of poly-substance use prevention programs, especially if targeted to the students in higher grades who appear to be at the greatest risk [10].

There is a complex inter-relationship between overweight and obesity with sedentary behaviours, physical inactivity, and diet. There is emerging interest in examining the impact sedentary lifestyles are having on youth health [44], as youth obesity trends coincide with the prevalence of youth reporting more than four hours of screen time per day [45]. Although our results suggest that over one in five Canadian secondary school students is overweight or obese, prevalence rates of overweight and obesity remained relatively stable across grades. This was surprizing considering our data show that rates of physical inactivity increase dramatically across grades, but it may also be a function of missing BMI data. Even more alarming was our finding that rates of inadequate fruit and vegetable consumption and sedentary behaviour were so high that there was little room for variation across grades due to the ceiling effect observed. These two characteristics were the most common modifiable risk factors for future disease and represent the immediate priority areas for action. Considering the high prevalence of these behaviours, even among students in grade 9, it is clear that intervention efforts to reduce sedentary behaviour and to increase fruit and vegetable intake must begin prior to secondary school.

\section{Limitations}

This study has several limitations common to survey research. Although the response rate was high and the data were weighted to help account for non-response, the findings are nevertheless subject to sample bias. In addition, the findings likely reflect some under-reporting for substance use and missing data for BMI as is common in survey research $[46,47]$. Although YSS data are based on self-reported measures, the questionnaire measures for current smoking, physical activity and BMI have previously demonstrated satisfactory reliability and validity $[35,36]$; the YSS measures for sedentary behaviour, alcohol use, marijuana use, and fruit and vegetable intake have not been previously validated. However, honest reporting was encouraged by ensuring confidentiality during data collection. It should also be noted that the cross-sectional nature of the design does not allow for causal inferences regarding trends over time. Longitudinal data are required to determine the temporal sequence of the onset of use for these substances and behaviours.

\section{Conclusions}

In sum, the finding that large proportions of graduating students fail to meet many or most health behaviour guidelines should give all stakeholders cause for concern. It is clear that we need effective models of intervention. In order to reduce the impending burden associated with current rates of these modifiable risk factors for disease among youth populations in Canada, there is a need to re-orient prevention efforts aimed at modifying these individual behaviours into areas which offer the potential for population-wide impact [48]. A population-level intervention approach that changes the environment surrounding youth may have greater potential to affect long-term population-level reductions in youth risk behaviours $[49,50]$. Research has shown that population impact is best understood using ecological theory, a perspective that views behaviour as involving relationships between the individual and the multiple contexts in which they are situated [51,52]. Among youth populations, a school represents an ecological environment that can influence risk behaviours since youth spend $\sim 25$ hours each week in school throughout the school year where they could be influenced by people, programs, policies or the built environment (resources) to promote healthier lifestyles. Moreover, in order to optimize limited prevention resources, it may be even more beneficial if such population-level intervention efforts targeted multiple modifiable behavioural risk factors simultaneously. Considering the lack of current longitudinal research focusing on multiple risk behaviours in Canada, there is an immediate need for ongoing surveillance, research and evaluation on youth risk behaviours and the school-level 
characteristics (programs, policies, resources) associated with those behaviours which are amenable to modification.

\section{Endnote}

${ }^{\mathrm{a}}$ As a result of some wording differences for measuring fruit and vegetable intake between the English and French language questionnaires used in the 2010 YSS (as outlined in the 2010 YSS user guide), we could not differentiate between French language female respondents who had 6 or 7 servings of fruit or vegetables per day. As such, for these French language female respondents $(16.7 \%$ of all females), we decided to use a more conservative estimate of fruit and vegetable intake based on the data available, where the French language female respondents were deemed as having inadequate fruit and vegetable intake if they consumed less than six servings per day.

\section{Abbreviations}

BMl: Body mass index; CDC: Centers for disease control and prevention; CHMS: Canadian health measures survey; NLSCY: National longitudinal survey of children and youth; PA: Physical activity; PHAC: Public Health Agency of Canada; YRBSS: Youth risk behavior Surveillance system; YSS: Youth smoking survey.

\section{Competing interests}

Both authors declare that they have no competing interests.

\section{Authors' contributions}

SL conceived the purpose, design and analyses for the study, led the interpretation of data, led the writing of the manuscript, developed the table and figures, and gave final approval of the version to be published. VR performed the analyses, reviewed the drafted the article and provided critical input, and gave final approval of the version to be published.

\section{Acknowledgement}

The Youth Smoking Survey is a product of the pan-Canadian capacity building project funded through a contribution agreement between Health Canada and the Propel Centre for Population Health Impact from 2004 to 2007 and a contract between Health Canada and the Propel Centre for Population Health Impact from 2008-2011. The YSS consortium includes Canadian tobacco control researchers from all provinces and provided training opportunities for university students at all levels. The views expressed herein do not necessarily represent the views of Health Canada.

\section{Author details}

${ }^{1}$ School of Public Health and Health Systems, University of Waterloo, 200 University Avenue, Waterloo ON, N2L 3G1, Canada. ${ }^{2}$ Propel Centre for Population Health Impact, University of Waterloo, 200 University Avenue, Waterloo ON, N2L 3G1, Canada.

\section{Received: 20 December 2012 Accepted: 5 June 2013}

Published: 11 June 2013

\section{References}

1. Horton ES: Effects of lifestyle changes to reduce risks of diabetes and associated cardiovascular risks: results from large scale efficacy trials. Obesity 2009, 17:S43-S48.

2. American Dietetic Association: Position of the American Dietetic Association: individual-, family-, school-, and community-based interventions for pediatric overweight. J Am Dietetic Assoc 2006, 106:925-945.

3. U.S. Department of Health and Human Services: The health consequences of smoking. Atlanta: U.S. Department of Health and Human Services, Public Health Service, Centers for Disease Control and Prevention, National Center for Chronic Disease Prevention and Health Promotion, Office of Smoking and Health; 2004.

4. World Health Organization: Diet, nutrition and the prevention of chronic diseases. Joint WHO/FAO Expert Consultation on Diet, Nutrition and the Prevention of Chronic Diseases. Geneva, Switzerland: WHO Technical Report Series (916); 2003.
5. Adami HO, Day NE, Trichopoulos NE, Willett WC: Primary and secondary prevention in the reduction of cancer morbidity and mortality. Eur $J$ Cancer 2001, 37:S118-S127.

6. Trost SG, Kerr LM, Ward DS, Pate RR: Physical activity and determinants of physical activity in obese and non-obese children. Int J Obesity 2001, 25:822-829.

7. Hall W: Cannabis use and public health: assessing the burden. Addiction 2000, 95:485-490.

8. U.S. Department of Health and Human Services: Physical Activity and Health: A Report of the Surgeon General. Centers for Disease Control and Prevention, National Center for Chronic Disease Prevention and Health Promotion. The President's Council on Physical Fitness and Sports; 1999.

9. Colditz GA, DeJong W, Hunter D, Trichopoulos D, Willett W: Harvard report on cancer prevention. Volume 1: Causes of Human Cancer. Cancer Causes Control 1996, 7:S3-S58.

10. Leatherdale ST, Burkhalter R: The substance use profile of Canadian youth: exploring the prevalence of alcohol, drug and tobacco use by gender and grade. Addict Behav 2012, 37:318-322.

11. Leatherdale ST, Ahmed R: Screen-based sedentary behaviours among a nationally representative sample of youth: are Canadian kids couch potatoes? Chronic Dis Inj Can 2011, 31:141-146.

12. Tremblay $M$, Shields M, Laviolette $M$, Craig $C L$, Janssen I, Connor Gorber S: Fitness of Canadian Children and Youth: Results from the 2007-2009 Canadian Health Measures Survey. Health Rep 2010, 21:1-7.

13. Colley RC, Garriguet D, Janssen I, Craig CL, Clarke J, Tremblay MS: Physical activity of Canadian children and youth: Accelerometer results from the 2007 to 2009 Canadian Health Measures Survey. Health Rep 2011, 22:15-23.

14. Statistics Canada: Fruit and vegetable consumption; 2011. http://www.statcan.gc. ca/pub/82-625-x/2012001/article/11661-eng.htm.

15. Ezzati M, Vander Hoorn S, Lopez AD, Danaei G, Rodgers A, Mathers CD, Murray CJL: Chapter 4 Comparative Quantification of Mortality and Burden of Disease Attributable to Selected Risk Factors. In Global Burden of Disease and Risk Factors. Edited by Lopez AD, Mathers CD, Ezzati M, Jamison DJ, Murray CJL. Washington DC, USA: Oxford University Press and The World Bank; 2006.

16. Centers for Disease Control and Prevention: Youth risk behaviour surveillance - United States, 2007. MMWR 2008, 57:SS-4.

17. Wong SL, Leatherdale ST: Association between sedentary behavior, physical activity, and obesity: inactivity among active kids. Prev Chronic Dis 2009, 6:A26.

18. Leatherdale ST, Wong SL, Manske SR, Colditz GA: Susceptibility to smoking and its association with physical activity, BMI, and weight concerns among youth. Nicotine Tob Res 2008, 10:499-505.

19. Botvin GJ, Griffin KW: School-based programmes to prevent alcohol, tobacco and other drug use. Int Rev Psychiatry 2007, 19:607-615.

20. Anderson P: Global use of alcohol, drugs and tobacco. Drugs Alcohol Rev 2006, 25:489-502.

21. Butt P, Beirness D, Gliksman L, Paradis C, Stockwell T: Alcohol and health in Canada: A summary of evidence and guidelines for low-risk drinking. Ottawa, ON: Canadian Centre on Substance Abuse; 2011.

22. Canadian Society for Exercise Physiology: Canadian Physical Activity Guidelines for Youth - 12 to 17 years. http://www.csep.ca/CMFiles/Guidelines/CSEPInfoSheets-youth-ENG.pdf.

23. Canadian Society for Exercise Physiology: Canadian Sedentary Behaviour Guidelines for Youth - 12 to 17 years. http://www.csep.ca/CMFiles/Guidelines/ CSEP-InfoSheets-ENG-Teen\%20FINAL.pdf.

24. Fisher $B$, Jeffries $V$, Hall W, Room R, Goldner E, Rehm J: Lower risk cannabis guidelines for Canada (LRCG): a narrative review of evidence and recommendations. Can J Public Health 2011, 102:324-327.

25. Health Canada: Eating Well with Canada's Food Guide. http://www.hc-sc.gc.ca/fnan/alt_formats/hpfb-dgpsa/pdf/food-guide-aliment/print_eatwell_bienmangeng.pdf.

26. World Health Organization: Growth reference 5-19 years; 2007. http://www.who. int/growthref/who2007_bmi_for_age/en/index.html.

27. Alamian A, Paradis G: Individual and social determinants of multiple chronic disease behavioral risk factors among youth. BMC Public Health 2012, 12:224.

28. Alamian A, Paradis G: Clustering of chronic disease behavioral risk factors in Canadian children and adolescents. Prev Med 2009, 48:493-499.

29. Alamian A, Paradis G: Correlates of multiple chronic disease behavioral risk factors in Canadian children and adolescents. Am J Epidemio/ 2009, 170:1279-1289. 
30. Statistics Canada: National Longitudinal Survey of Children and Youth (NLSCY); 2010. $\mathrm{http} / / \mathrm{mw} w 23$. statcan.gc.ca/imdb/p2SV.pl?Function = getSurvey\&SDDS = 4450\&ltem_ld = 25609\&lang = en.

31. Veugelers PJ, Schwartz ME: Comprehensive school health in Canada. Can J Public Health 2010, 101:S5-S8.

32. International Union Health Promotion and Education: Achieving health promoting schools: Guidelines for promoting health in schools. Saint-Denis Cedex, France: International Union Health Promotion and Education; 2009.

33. WHO Regional Office for the Western Pacific: Regional guidelines development of health promoting schools: A framework for action. Manila, Philippines: WHO Regional Office for the Western Pacific; 1996.

34. University of Waterloo: Youth Smoking Survey (YSS): 2010/2011 YSS Microdata User Guide. Waterloo, ON: Propel Centre for Population Health Impact; 2011.

35. Wong S, Leatherdale ST, Manske S: Reliability and validity of a school-based physical activity questionnaire. Med Sci Sport Exerc 2006, 38:1593-1600.

36. Wong SL, Shields M, Leatherdale S, Malaison E, Hammond D: Assessment of validity of self-reported smoking status. Health Rep 2012, 23:1-7.

37. SAS Institute Inc: The SAS System for Windows. Cary, NC: SAS Institute Inc;; 2001.

38. Eaton DK, Kann L, Kinchen S, Shanklin S, Flint KH, Hawkings J, Harris WA Lowry R, McManus T, Chyen D, Whittle L, Lim C, Wechsler H: Youth risk behavior surveillance - United States, 2011. MMWR 2012, 61:1-47.

39. Schmid B, Hohm E, Blomeyer D, Zimmermann US, Schmidt MH, Esser G, Laucht M: Concurrent alcohol and tobacco use during early adolescence characterizes a group at risk. Alcohol Alcohol 2007, 42:219-225.

40. DeWit DJ, Adlaf EM, Offord DR, Ogborne AC: Age at first alcohol use: a risk factor for the development of alcohol disorders. Am J Psychiatry 2000, 157:745-750.

41. Leatherdale ST, Ahmed R: Alcohol, marijuana, and tobacco use among Canadian youth: do we need more multi-substance prevention programming? J Prim Prev 2010, 31:99-108.

42. Ringwalt C, Hanley S, Vincus AA, Ennett ST, Rohrbach LA, Bowling JM: The prevalence of effective substance use prevention curricula in the Nation's high schools. J Prim Prev 2008, 29:479-488.

43. Wiefferink CH, Peters L, Hoekstra F, Dam GT, Buijs GJ, Paulussen TGWM: Clustering of health-related behaviors and their determinants: possible consequences for school health interventions. Prev Sci 2006, 7:127-149.

44. Marshall SJ, Biddle SJ, Gorely T, Cameron N, Murdey I: Relationships between media use, body fatness, and physical activity in children and youth: a meta-analysis. Int J Obes Relat Metab Disord 2004, 28:1238-1246.

45. Crespo CJ, Smit E, Troiana RP, Bartlett SJ, Marcera CA, Andersen RE: Television watching, energy intake, and obesity in U.S. children: results from the third National Health and Nutrition Examination Survey, 1988-1994. Arch Pediatr Adolesc Med 2001, 155:360-365.

46. Bovet $P$, Viswanathan $B$, Faeh D, Warren W: Comparison of smoking, drinking, and marijuana use between students present or absent on the day of a school-based survey. J School Health 2006, 76:133-137.

47. Arbour-Nicitopoulos KP, Faulker GE, Leatherdale ST: Learning from non-reported data: interpreting missing Body Mass Index values in young children. Measurement Phys Educ Exerc Sci 2010, 14:241-251.

48. Kickbush I: Approaches to an ecological base for public health. Health Promotion Int 1989, 4:265-268.

49. Rose G: The strategy of preventive medicine. Oxford: Oxford University Press; 1992.

50. Green LW, Kreuter MW: Health Program Planning: An Ecological and Educational Approach. 4th edition. Boston: McGraw-Hill; 2004.

51. Lerner RM, Ostrom CW, Freel MA: Preventing health-compromising behaviors among youth and promoting their positive development: A developmental contextual perspective. In Health Risks and Developmental Transitions During Adolescence. Edited by Schulenberg J, Hurrelmann K. New York, NY: Cambridge University Press; 1997:498-521.

52. Bronfenbrenner U: The ecology of human development: experiments by nature and design. Cambridge, MA: Harvard University Press; 1979.

\section{doi:10.1186/1471-2458-13-569}

Cite this article as: Leatherdale and Rynard: A cross-sectional examination of modifiable risk factors for chronic disease among a nationally representative sample of youth: are Canadian students graduating high school with a failing grade for health?. BMC Public Health 2013 13:569.

\section{Submit your next manuscript to BioMed Central and take full advantage of:}

- Convenient online submission

- Thorough peer review

- No space constraints or color figure charges

- Immediate publication on acceptance

- Inclusion in PubMed, CAS, Scopus and Google Scholar

- Research which is freely available for redistribution

Submit your manuscript at www.biomedcentral.com/submit
() Biomed Central 